\title{
Evaluation of Inverse Modeling Techniques for Pinpointing Water Leakages at Building Constructions
}

\author{
A. W. M. van Schijndel \\ Unit Building Physics and Services, Department of the Built Environment, Eindhoven University of Technology, \\ Eindhoven, Netherlands \\ Email: A.W.M.v.Schijndel@tue.nl
}

Received 9 October 2014; revised 19 November 2014; accepted 26 December 2014

Copyright @ 2015 by author and Scientific Research Publishing Inc.

This work is licensed under the Creative Commons Attribution International License (CC BY). http://creativecommons.org/licenses/by/4.0/

(c) (i) Open Access

\begin{abstract}
The location and nature of the moisture leakages are sometimes difficult to detect. Moreover, the relation between observed inside surface moisture patterns and where the moisture enters the construction is often not clear. The objective of this paper is to investigate inverse modeling techniques as a tool for the detection of moisture leakage locations in building constructions from inside surface moisture patterns. It is concluded that although the presented methodology is promising, more research is needed to confirm its usability.
\end{abstract}

\section{Keywords}

Inverse Modeling, Building, Construction, Moisture, Leakage

\section{Introduction}

Hunting Lodge St. Hubertus is one of the most prominent buildings from the beginning of the twentieth century and is noted in the top 100 list of Dutch monuments. The conservation of the building and its interior are of great importance. The Dutch Government Building Department, which takes care of the maintenance of the building, has expressed their concern about the observed damage due to high moisture levels by the rain that finds its way to the interior at places of inadequate detailing and therefore causes damage mainly near openings in the facade and on the inside of the facade below balconies. The main problem is that the location and nature of the moisture leakages are not easily detectable. We often don't know the relation between the observed inside surface moisture patterns and where the moisture enters the construction. The objective is to investigate inverse modeling techniques as a tool for the detection of moisture leakage locations in building constructions, i.e. we 
want to investigate the (in)possibilities of pinpointing moisture leakages from inside surface moisture patterns using inverse modeling techniques.

\subsection{Summary of the Observed Moisture Problems at the Hunting Lodge St. Hubertus}

Hunting Lodge St. Hubertus is located on the northern side of the Dutch National Park "De Hoge Veluwe”. The Hunting Lodge is built as a guesthouse between 1916 and 1922, by Holland's most well-known architect from that time, H. P. Berlage. The building consists of a low-rise rectangular volume with wings that stretch out diagonally and with a characteristic high tower of over 30 meters height in the middle of the building (see Figure 1). A large pond is situated south-west of the building and the building is surrounded by forest in all other directions.

The damage that occurs in the tower was systematically inspected to enable a thorough assessment of the possible causes of the moisture problems by Briggen et al. (2009). The damage on the inside of the tower, and where possible also on the outside, is systematically inspected. The location and type of each moisture problem are documented in a table, illustrated with a picture of the damage. The moisture problems that manifest themselves in the tower of the Hunting Lodge can be divided in the following categories: efflorescence, cracking, soiling, moist spots, mechanical damage and biological growth.

A few pictures of the moisture damage that occurs in the tower are shown in Figure 2 (Briggen et al. [1]).

Regarding the location of the damage it can be concluded from the inspection that most damage occurs on the interior surface of the south-west facade of the tower. Since the prevailing wind direction in the Netherlands is south-west, which means that the south-west facade of the tower is subjected to wind-driven rain the most, there appears to be a connection between the rain load of the facade and the damage on the inside. There are no clear differences between the damage on lower or higher floors or between the damage on the middle and on the sides of the facade. Most damage occurs near openings in the facade and on the interior surface of the facade below balconies.

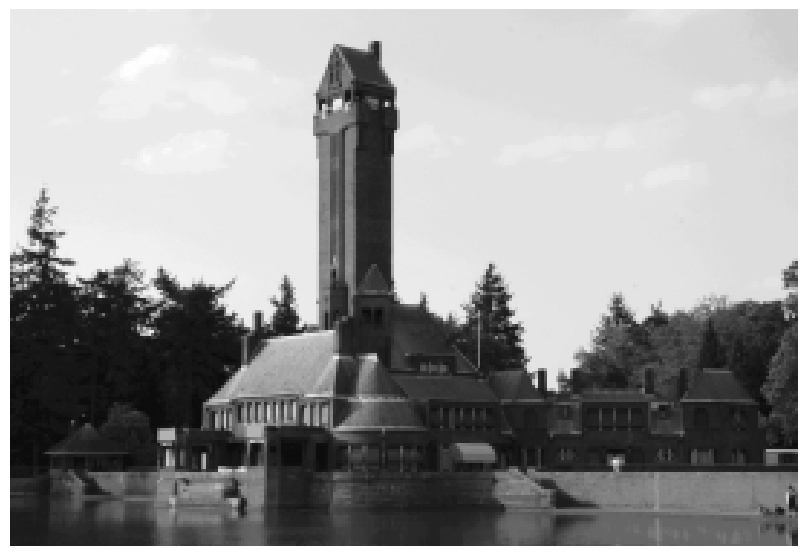

Figure 1. Hunting lodge St. Hubertus.
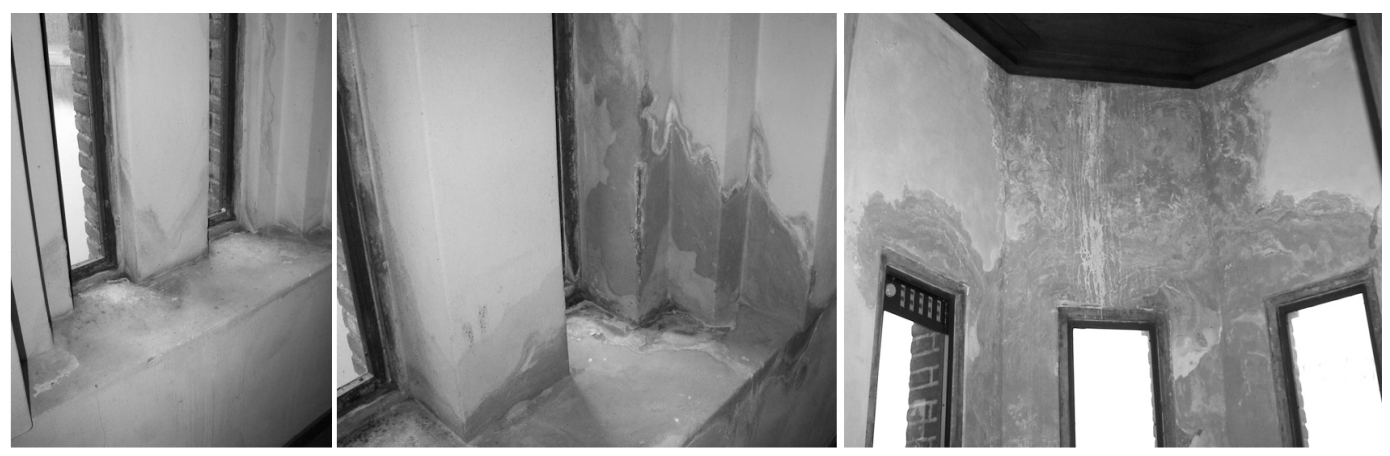

Figure 2. Observed moisture damage in the tower of the building: moist spots and efflorescence. 


\subsection{Methodology}

The research method contained the following steps:

(Step 1) Measurements of the external climate, indoor climate and surface conditions (Section 2).

(Step 2) Computational model development and calibration of the parameters (Section 3).

(Step 3) From one of the prominent observed moisture spot, an inverse modeling technique was used to determine the moisture entrance for pinpointing the most likely water leakage (Section 4).

(Step 4) Discussion and conclusions of the approach (Section 5).

\section{Measurements}

The data set is part of the measurement program at the Hunting Lodge St. Hubertus site, performed during 20062007 by Briggen [1]. Details of this project can be found in Briggen et al. [2] [3]. One of problems seemed to be high moisture contents at the inside surface of the facade of the tower. The construction of this facade is shown in Figure 3.

The outside climate conditions were measured by a weather station within $50 \mathrm{~m}$ from the building. The inside air temperature and relative humidity were measured using standard equipment (see Figure 4). A representation of inside surface conditions was obtained by placing a small box $(5 \mathrm{~cm} \times 5 \mathrm{~cm} \times 1 \mathrm{~cm})$ against the wall and measures the air temperature and relative humidity inside. The estimation of the measurement error of this method is left over for future research.

The data consists of the measured time series of the indoor and outdoor climate as presented in Figure 5 and Figure 6.
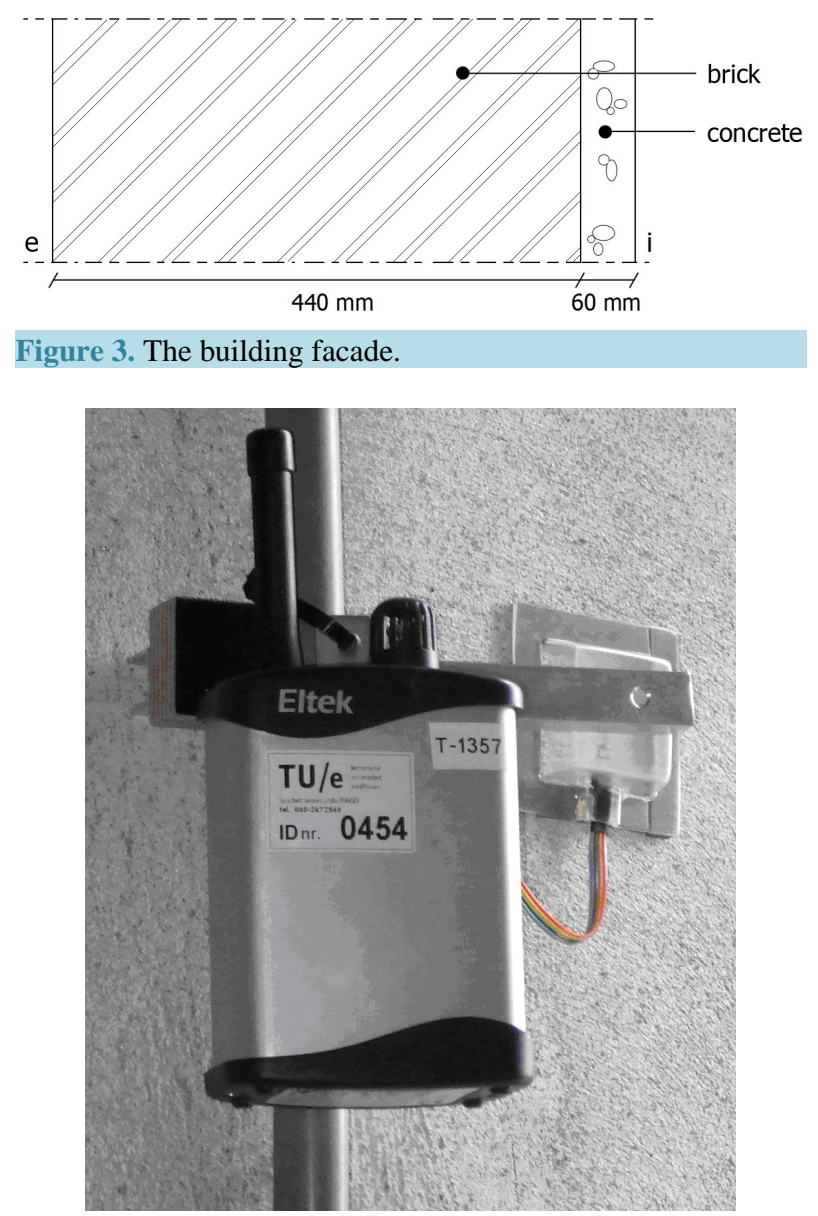

Figure 4. Measurement of the surface temperature and relative humidity using a box. 

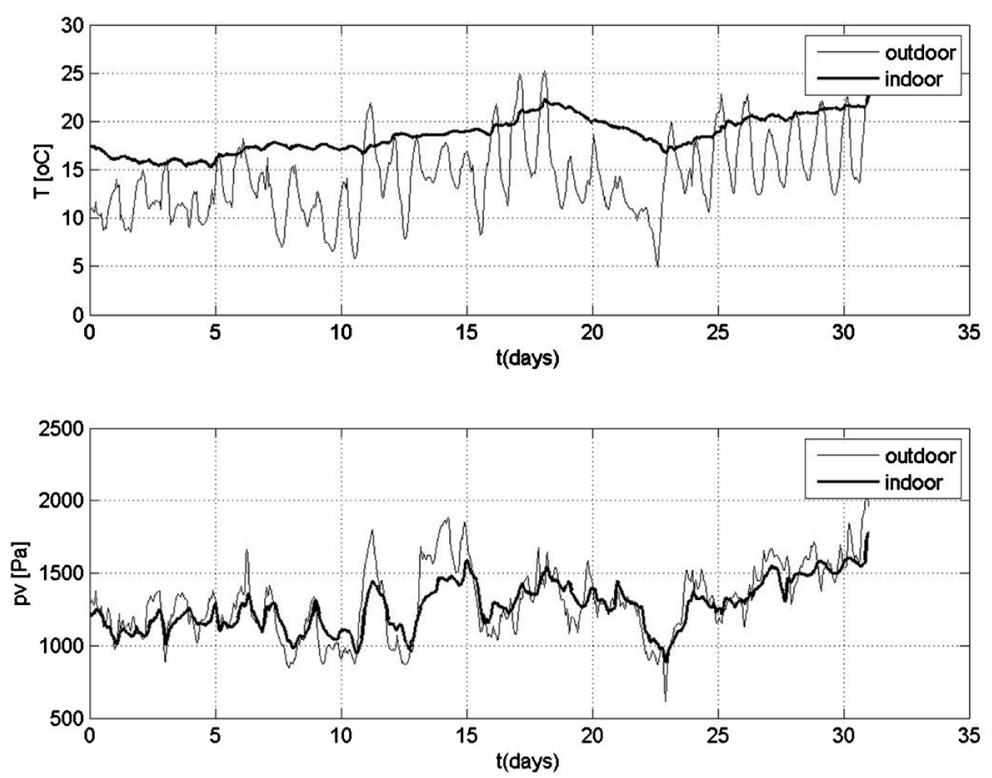

Figure 5. The measured air temperatures (top) and calculated vapour pressures (bottom, from measured T/RH).
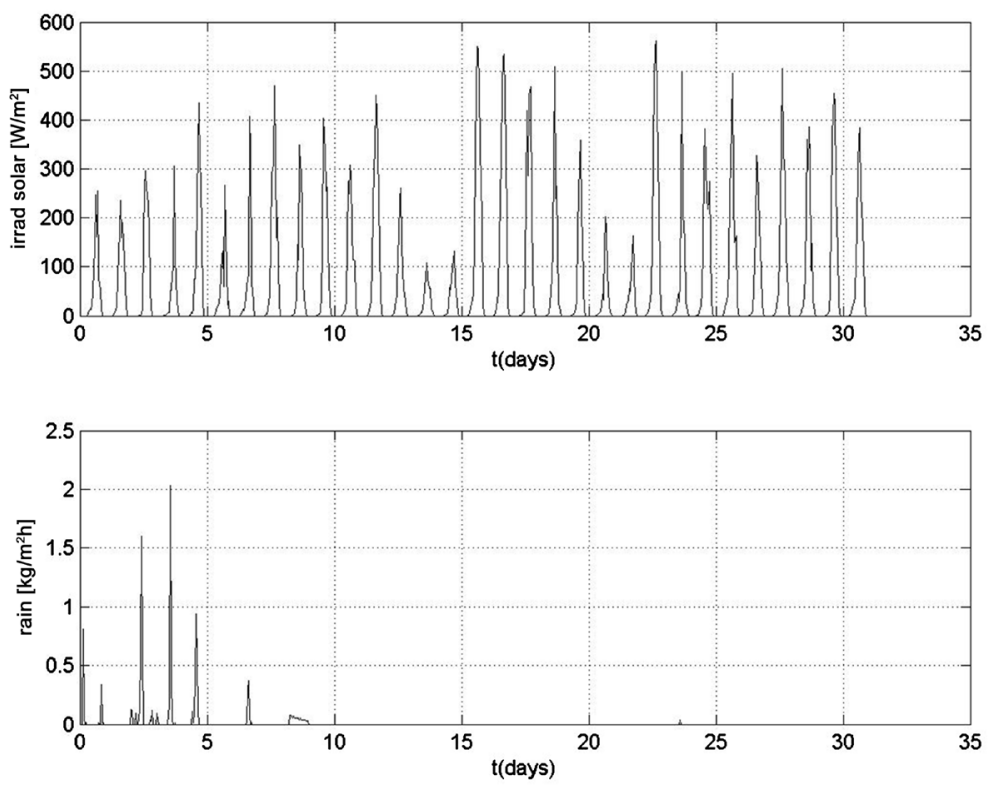

Figure 6. The measured solar irradiance (top) and rain intensity (bottom).

\section{Modeling}

The multiphysics modeling approach of van Schijndel [4]-[6] is used. The heat and moisture transport can be described by the following PDEs:

$$
\begin{gathered}
C_{T} \frac{\partial T}{\partial t}=\nabla \cdot\left(K_{11} \nabla T+K_{12} \nabla L P c\right) \\
C_{L P c} \frac{\partial L P c}{\partial t}=\nabla \cdot\left(K_{21} \nabla T+K_{22} \nabla L P c\right)
\end{gathered}
$$

where $t$ is time [s]; $T$ is temperature $\left[{ }^{\circ} \mathrm{C}\right]$; The reminder of the terms in the heat (1) and moisture Equation 
(2) are explained below:

$$
\begin{gathered}
L P C={ }^{10} \log (P c) \\
C_{T}=\rho \cdot c \\
K_{11}=\lambda \\
K_{12}=-l_{l v} \cdot \delta_{p} \cdot \phi \cdot \frac{\partial P c}{\partial L P c} \cdot \text { Psat } \cdot \frac{M_{w}}{\rho_{a} R T} \\
C_{L P c}=\frac{\partial w}{\partial P C} \cdot \frac{\partial P c}{\partial L P C} \\
K_{22}=-K \cdot \frac{\partial P C}{\partial L P C}-\delta_{p} \cdot \phi \cdot \frac{\partial P c}{\partial L P c} \cdot \text { Psat } \cdot \frac{M_{w}}{\rho_{a} R T} \\
K_{21}=\delta_{p} \cdot \phi \cdot \frac{\partial P s a t}{\partial T}
\end{gathered}
$$

where $P c$ is capillary pressure $[\mathrm{Pa}] ; \quad \rho$ is material density $\left[\mathrm{kg} / \mathrm{m}^{3}\right] ; \quad c$ is specific heat capacity $[\mathrm{J} / \mathrm{kg} \cdot \mathrm{K}] ; \lambda$ is thermal conductivity $[\mathrm{W} / \mathrm{mK}] ; l_{l v}$ is specific latent heat of evaporation $[\mathrm{J} / \mathrm{kg}] ; \delta_{p}$ vapour permeability $[\mathrm{s}]$; $\phi$ is relative humidity [-]; Psat is saturation pressure [Pa]; $M_{w}=0.018[\mathrm{~kg} / \mathrm{mol}] ; R=8.314[\mathrm{~J} / \mathrm{mol} \cdot \mathrm{K}]$; $\rho_{a}$ is air density $\left[\mathrm{kg} / \mathrm{m}^{3}\right] ; w$ is moisture content $\left[\mathrm{kg} / \mathrm{m}^{3}\right] ; K$ is liquid water permeability [s].

MatLab is used for the implementation of material and boundary properties. These functions are used to convert measurable material properties such as $K, \phi, \delta_{p}$ and $\lambda$ which are dependent on the moisture content into PDE coefficients which are dependent on the $L P c$ and $T$. This is schematically shown in Figure 7.

The material database of DELPHIN [7] is used to provide material properties for the first guess. For brick, the Brick material properties of DELPHIN are used with constant $\rho=1700 ; c=840 ; \lambda=0.85$ and variable moisture properties using the tables. For concrete, the Lime plaster properties of DELPHIN

$(\rho=1800 ; c=840 ; \lambda=1.05)$ are used in the same way. From these data, the PDE coefficients were determined together with the boundary conditions implemented using the COMSOL [8] model of Section 3. Figure 8 and Figure 9 show the results.

Figure 8 shows that the simulated inside surface temperature is already quite close to the measured one.

The simulated relative humidity at the inside surface of Figure 9 seems to be less close to the measured one compared to the previous figure. This gives also rise to the just mentioned questions. For each material and at each point the vapour pressure can be calculated using a similar corresponding function.

\section{Determination of Moisture Source Characteristics}

In this section we try to reproduce the following observed moisture spots (see Figure 10).

The modeling approach of the previous section was used. The mesh of (simplified) geometry is presented in Figure 11.

The first step of the inverse modeling procedure is to switch one or more boundary conditions from dry into wet and then investigate it's effect on the inside surface moisture print. For example, Figure 13 shows the simulated profile at the inner surface by switching the location provided in Figure 12 from dry into wet.

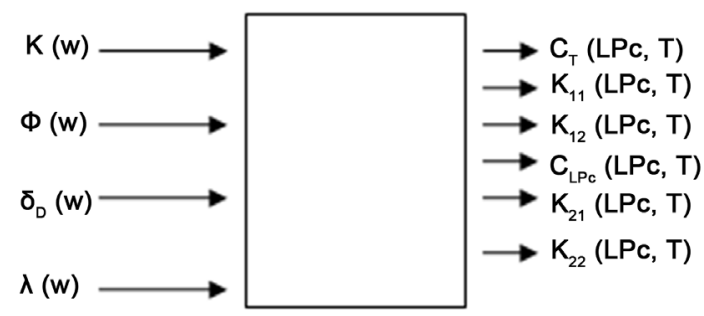

Figure 7. The conversion from measurable material properties into PDE coefficients. 


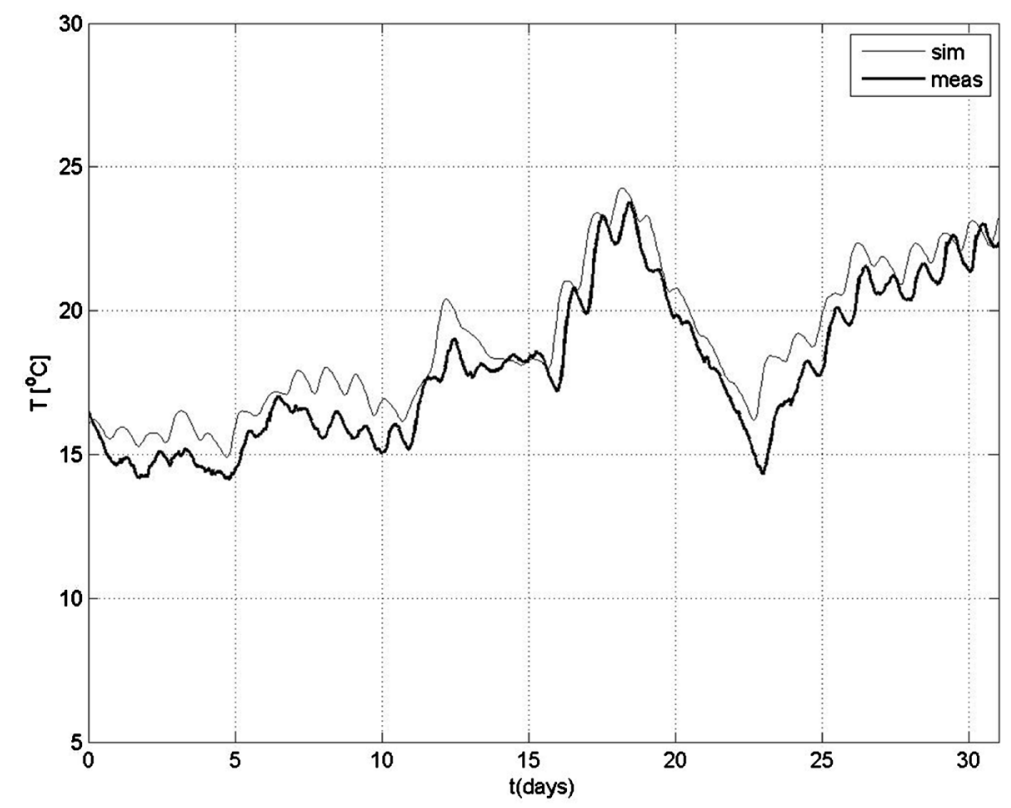

Figure 8. The measured and simulated inside surface temperature.

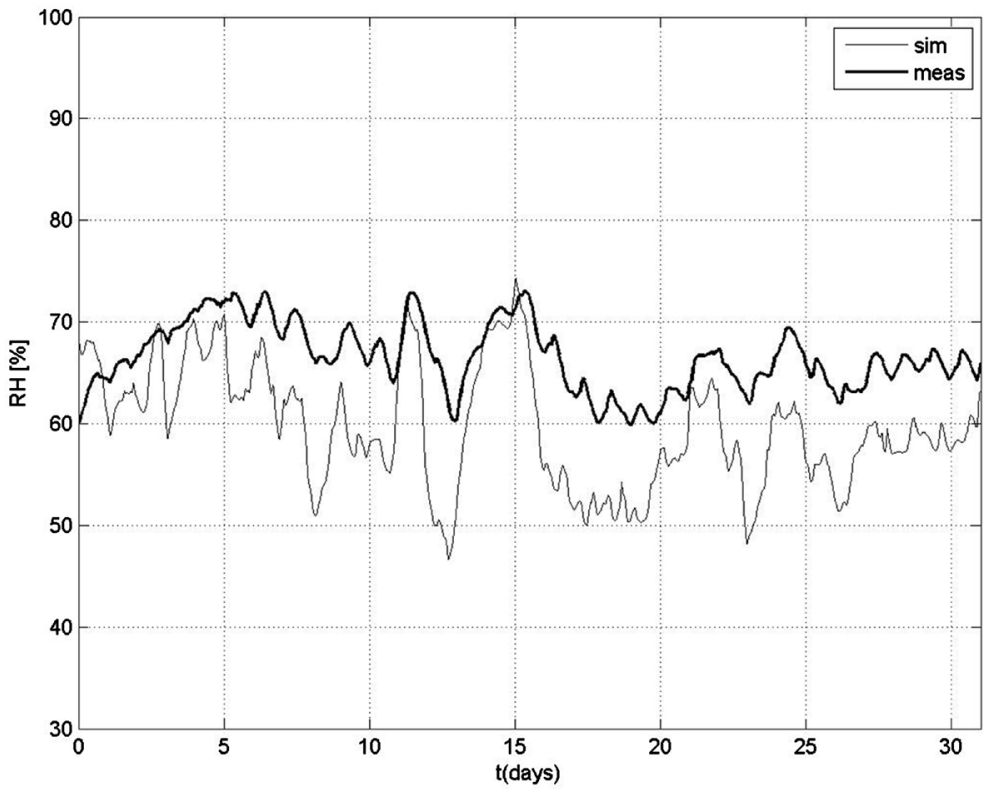

Figure 9. The measured and simulated relative humidity at the surface.

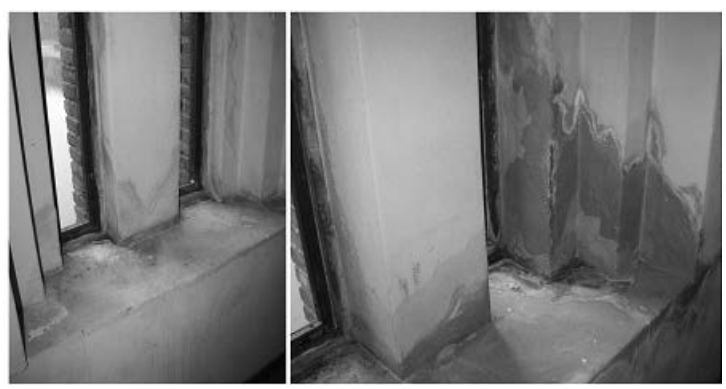

Figure 10. Observed moisture spots at the inner surface near the windows. 


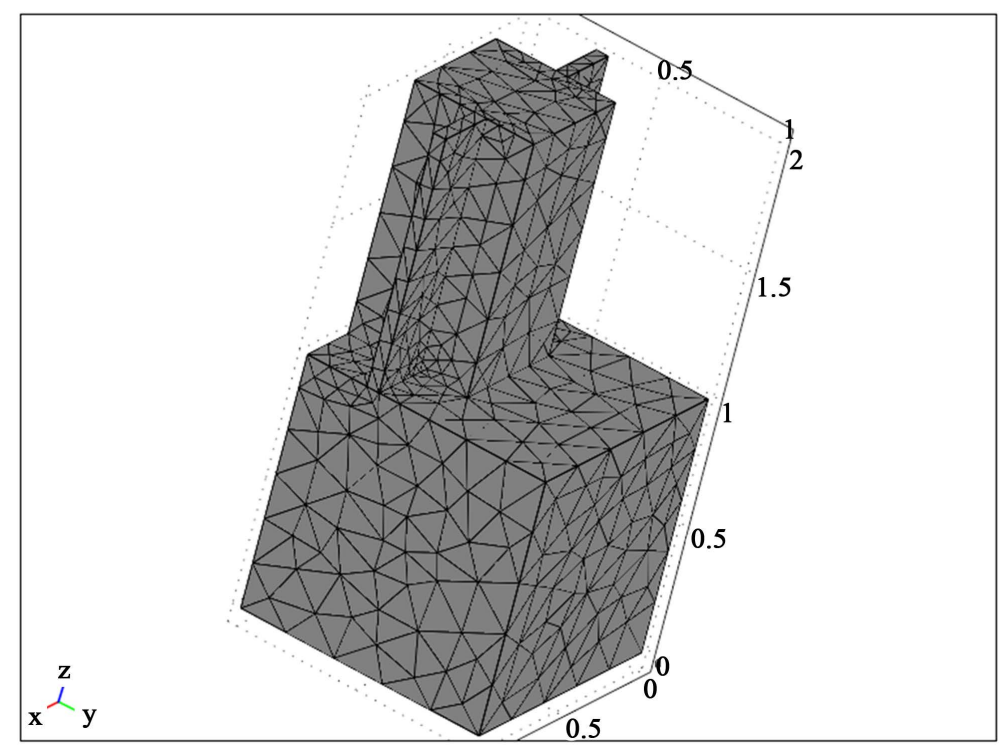

Figure 11. The mesh.

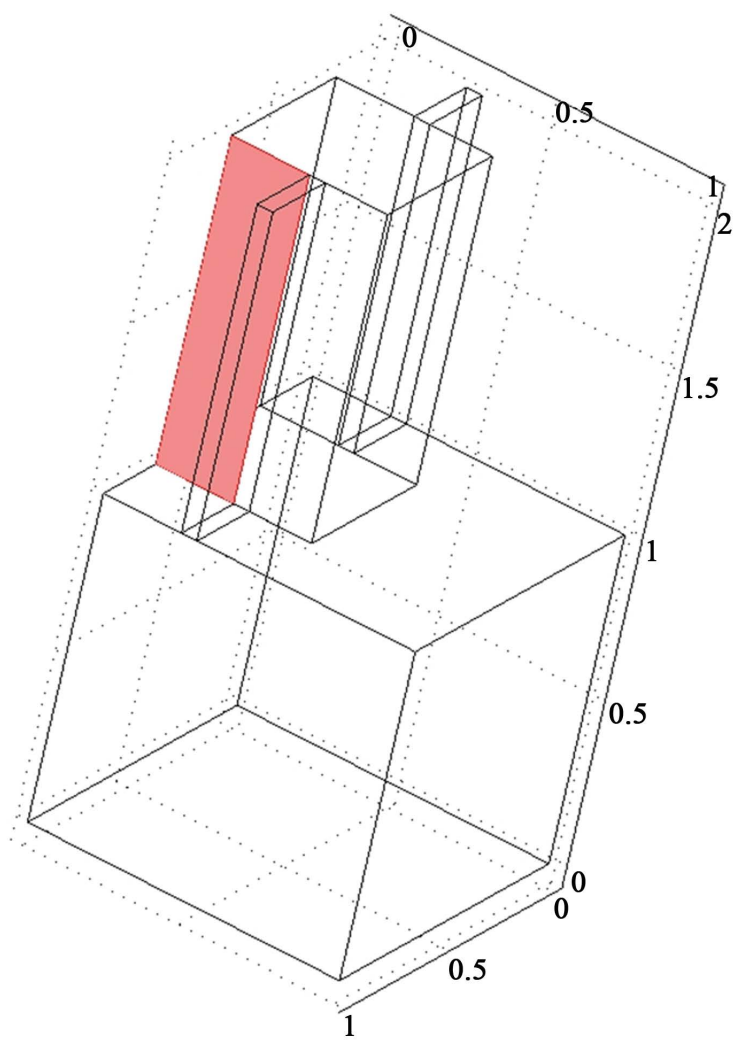

Figure 12. The location of the wet surface condition.

There is no match between the simulated profile at the inner surface of Figure 13 with the observed profile of Figure 10. Therefore it is concluded that the location of Figure 12 is not a possible candidate that causes the observed moisture spots.

In Appendix an overview is provided of nine more moisture profiles caused by corresponding possible wet locations. From these results, the best candidate for the moisture leakage location seems to be at the bottom of the window. 


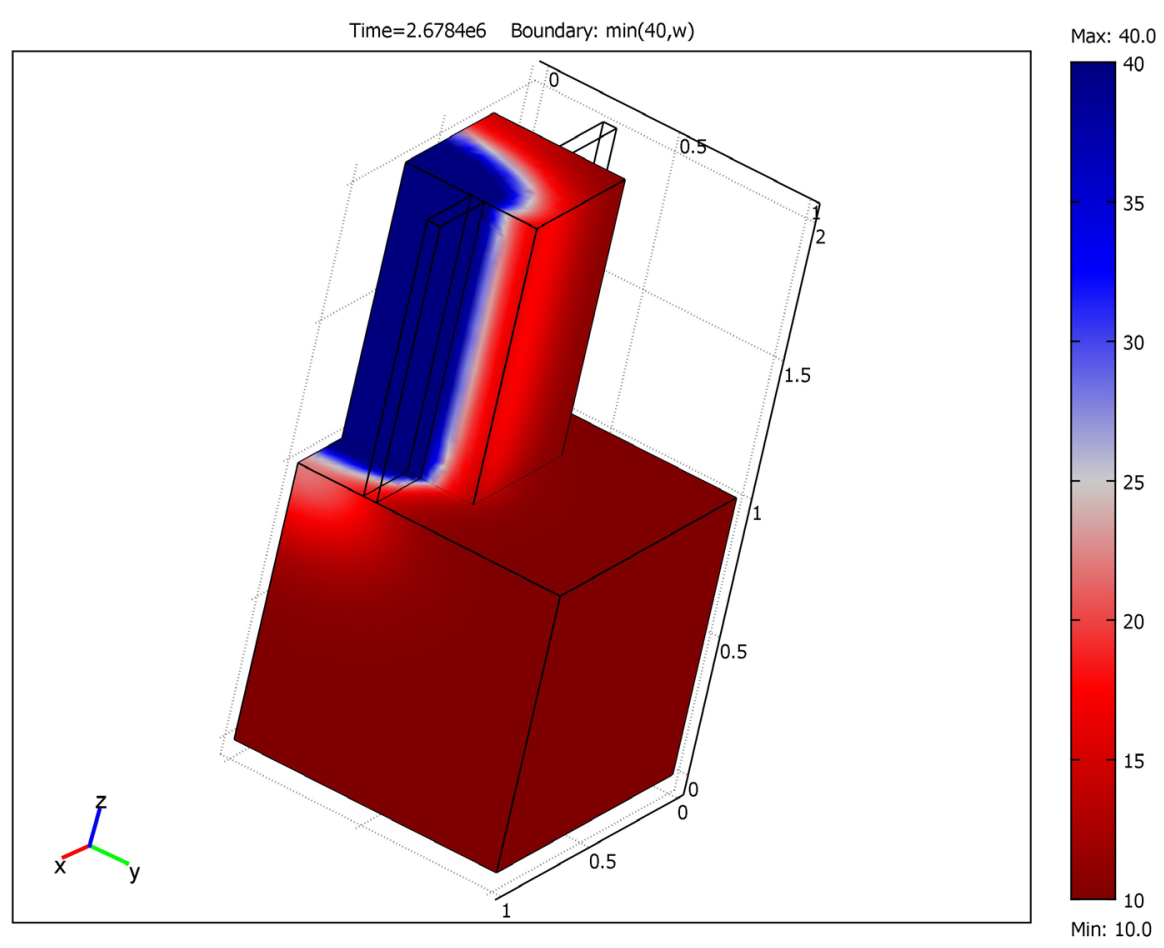

Figure 13. The steady state moisture pattern at the surfaces.

\section{Discussion and Conclusions}

This paper investigates the (in)possibilities of pinpointing moisture leakages from inside surface moisture patterns using inverse modeling techniques.

\subsection{Limitations}

1) In the presented method, the material properties were obtained from a database (DELPHIN [7]). In order to get very accurate simulation results, the material properties should be measured. This is however quite a problem because, often it is not allowed to take samples from monumental constructions. So the accuracy of the simulation results is limited. More research is needed to investigate exactly what the effect is of this uncertainty in the material properties.

2) The inverse modeling technique tries to match simulated moisture surface profiles with the observed moisture spots. It assumes a single "natural" cause, for example a leak between the window and brick caused by cracks. If a moisture spot is caused by some repair action, for example a complete replacement of the windows, this is not taken into account.

3) The current inverse modeling technique is still rather basic by manipulating the boundary conditions by hand. A more sophisticated method, where the boundary conditions are manipulated by a computer algorithm is under investigation.

\subsection{Future Research}

Future research include the testing of the method with laboratory experiments and a thoroughly evaluation of the approach as instrument for pinpointing the location of leakages. By selecting materials with well-known properties limitation (1) can be fixed. Also limitation (2) can be fixed because of the high level of control at the lab.

It is concluded that although the presented methodology is promising, more research is needed to confirm its usability.

\section{References}

[1] Briggen, P.M. (2007) A Study on the Moisture Problems at Hunting Lodge St. Hubertus. M.Sc. Thesis, Technische 
Universiteit Eindhoven, Eindhoven, 120 p. (In Dutch)

[2] Briggen, P.M., Blocken, B.J.E., van Schijndel, A.W.M. and Schellen, H.L. (2009) Wind-Driven Rain and Related Moisture Problems at the Tower of a Monumental Building. 4th International Building Physics Conference, 15-18 June 2009, Istanbul, 709-716.

[3] Briggen, P.M., Blocken, B.J.E. and Schellen, H.L. (2009) Wind-Driven Rain on the Facade of a Monumental Tower: Numerical Simulation, Full-Scale Validation and Sensitivity Analysis. Building and Environment, 44, 1675-1690.

[4] van Schijndel, A.W.M. (2007) Integrated Heat Air and Moisture Modeling and Simulation. Ph.D. Thesis, Technische Universiteit Eindhoven, Eindhoven, 200 p.

[5] van Schijndel, A.W.M. (2009) Integrated Modeling of Dynamic Heat, Air and Moisture Processes in Buildings and Systems Using SimuLink and COMSOL. Building Simulation: An International Journal, 2, 143-155.

[6] van Schijndel, A.W.M. (2009) The Exploration of an Inverse Problem Technique to Obtain Material Properties of a Building Construction. 4th International Building Physics Conference, 15-18 June 2009, Istanbul, 91-98.

[7] DELPHIN (2014) http://de.wikipedia.org/wiki/Delphin_(Software)

[8] COMSOL (2014) http://en.wikipedia.org/wiki/COMSOL 


\section{Appendix}
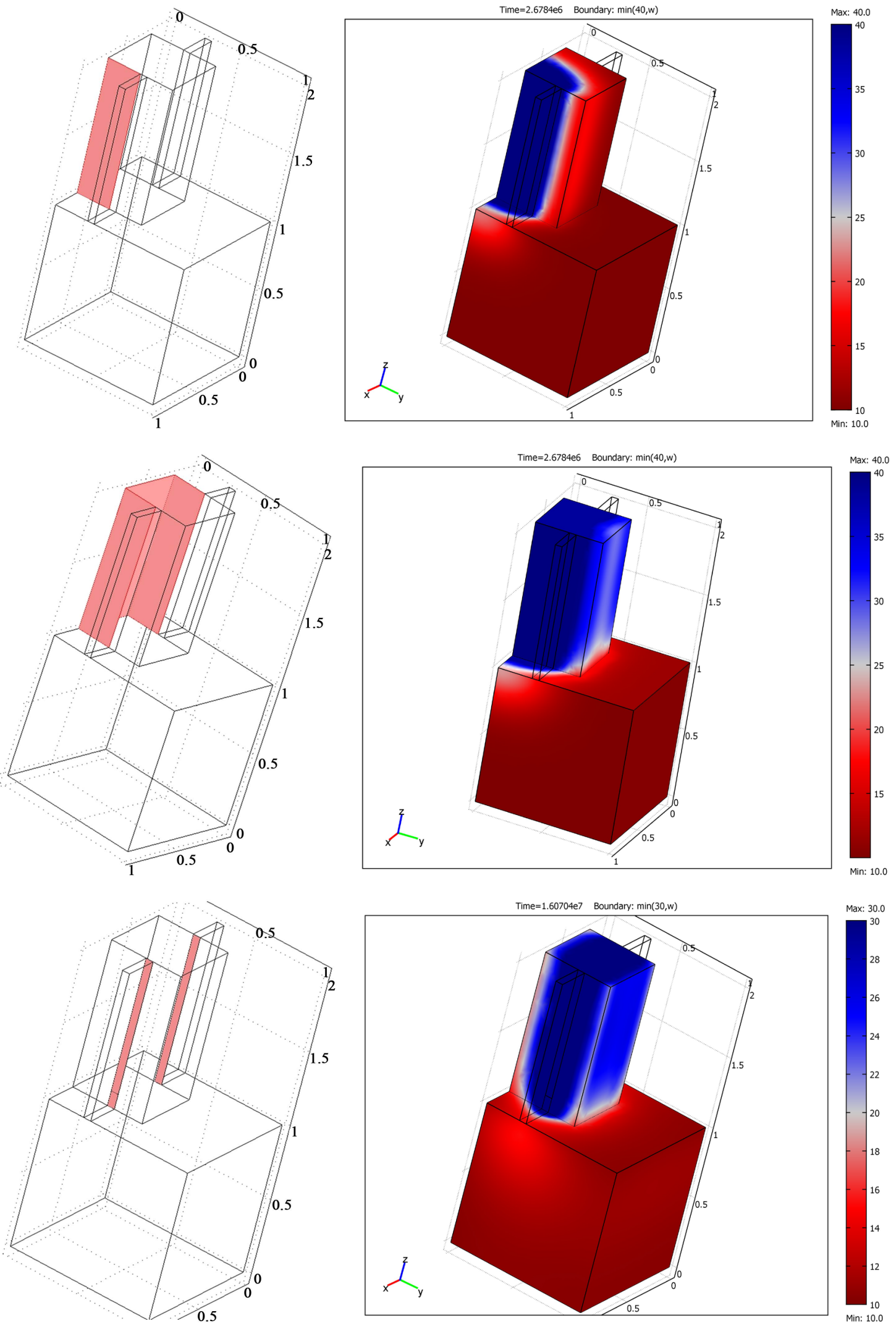
A. W. M. van Schijndel
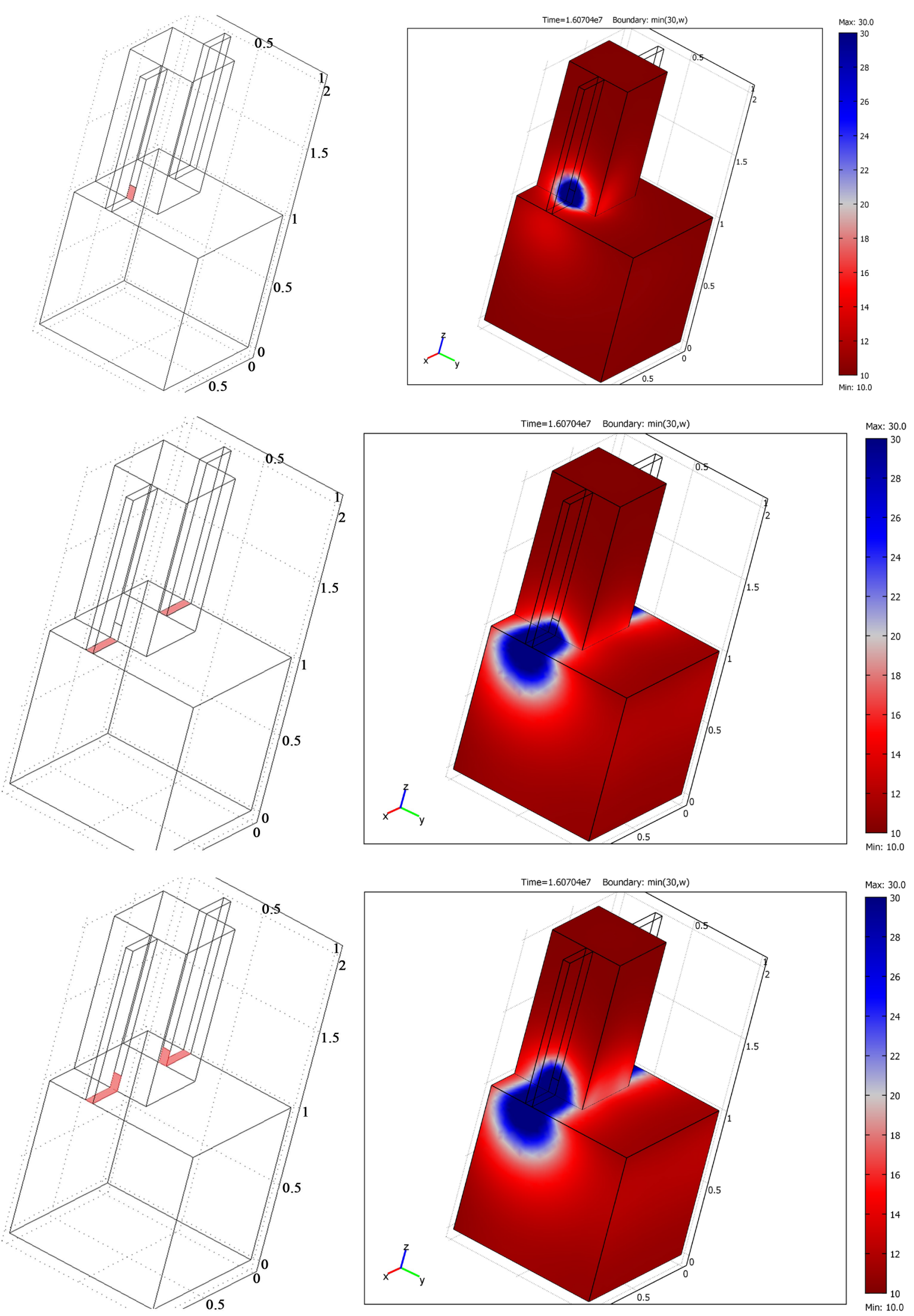
Scientific Research Publishing (SCIRP) is one of the largest Open Access journal publishers. It is currently publishing more than 200 open access, online, peer-reviewed journals covering a wide range of academic disciplines. SCIRP serves the worldwide academic communities and contributes to the progress and application of science with its publication.

Other selected journals from SCIRP are listed as below. Submit your manuscript to us via either submit@scirp.org or Online Submission Portal.
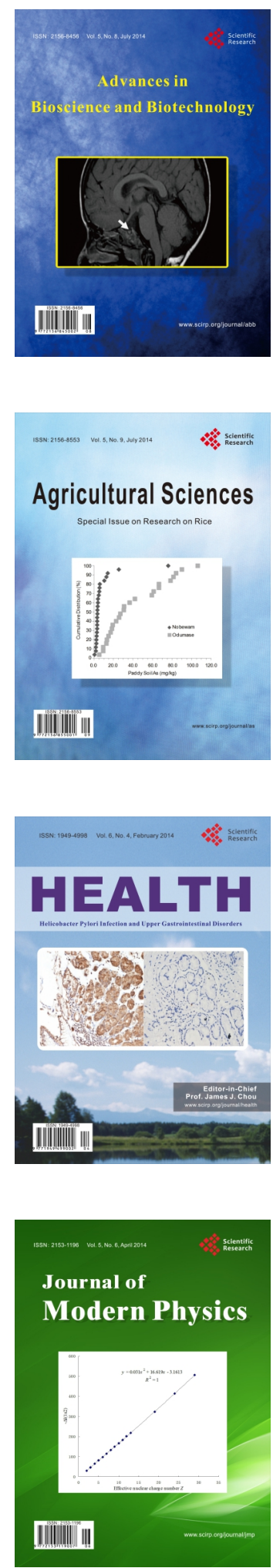
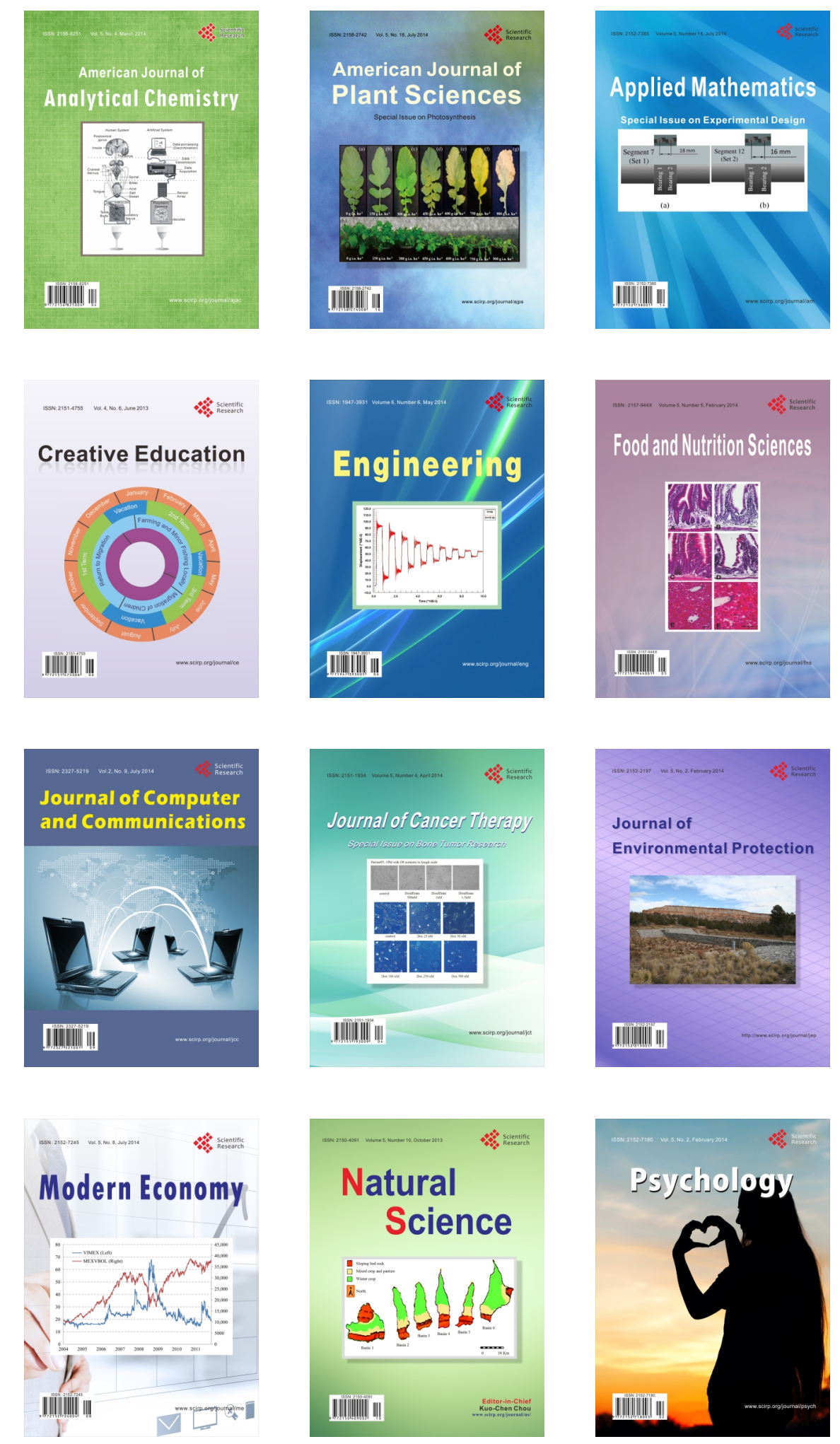